\title{
We Talk with Wes Schroll, CEO of Fetch Rewards, Softbank's latest Unicorn
}

\author{
Jon Eckhardt (University of Wisconsin-Madison)
}

KEYWORDS: Venture Capital, Startups, financing, startup finance, unicorn.

On April 1, Madison, Wisconsin-based company Fetch Rewards(https://www.fetchrewards.com) became a unicorn, with a $\$ 210$ million (https://www.prnewswire.com/news-releases/fetch-rewa rds-closes-210-million-round-of-funding-led-by-softbankvision-fund-2-301260323.html) investment round lead by SoftBank VisionFund 2. EIX Editor in Chief Jon Eckhardt interviewed the company's founder, Wes Schroll, on how he built Fetch Rewards in Madison, Wisconsin, into a billion-dollar company. This interview is a preview of our upcoming customer development series that will be launched soon at EIX.

\section{Highlights}

- Wes was 19 when he started Fetch Rewards in 2013

- In the startup phase staying focused on learning instead of immediate financial profit metrics can be a path towards finding a novel business model.

- Fetch Rewards worked closely with a local grocery store to discover the business model.

\section{Listen}

Link to video

EIX

(https://soundcloud.com/user-876519212-189256831).

Ch $10 \quad$ Wes $\quad$ Schroll

(https://soundcloud.com/user-876519212-189256831/c

h-10-wes-schroll) 